Jurnal Ilmiah Ibnu Sina, 6(2), Oktober 2021, 322-330

p-ISSN: 2502-647X; e-ISSN: 2503-1902

\title{
UJI AKTIVITAS TABIR SURYA DAN ANTIOKSIDAN EKSTRAK ETANOL DAUN SUNGKAI (Perenema canescens Jack)
}

\author{
Fadlilaturrahmah*, Amalia Khairunnisa, Aditya MP.Putra, Ivanna Sinta \\ Program Studi Farmasi, FMIPA, ULM, Indonesia \\ *Email: fadlilaturrahmah@ulm.ac.id
}

Artikel diterima: 23 Agustus 2021; Disetujui: 29 September 2021

DOI: https://doi.org/10.36387/jiis.v6i1.737

\begin{abstract}
ABSTRAK
Indonesia yang terletak di daerah tropis yang menyebabkan kulit masyarakatnya mudah mengalami penuaan dini dan kecokelatan. produk kosmetik tersebut sebagian besar mengandung bahan kimia sintetik yang berbahaya. Untuk itu, produk kosmetik berbahan aktif alami atau fitokosmetik yang efektif serta aman digunakan perlu dikembangkan. Salah satu tanaman bahan alam yang khas dari Kalimantan Selatan yang berpotensi dikembangkan sebagai sediaan kosmetik adalah Sungkai (Peronema canescens Jack). Tujuan penelitian untuk menentukan aktivitas antioksidan dan aktivitas tabir surya daun Sungkai. Metode yang digunakan untuk penetapan aktivitas antioksidan adalah metode DPPH menggunakan spektrofotometer uv-vis dan untuk penentuan aktivitas tabir surya menggunakan spektrofotometer uv-vis. Hasil penelitian menunjukan bahwa ekstrak tanaman P.canescens mengandung antrakuinon, flavonoid, saponin, tanin, dan fenol. Tanaman P.canescens memiliki Inhibitory Concentration $50\left(\mathrm{IC}_{50}\right)$ sebesar 42,219 $\pm 19,440 \mathrm{ppm}$ dan memiliki aktivitas tabir surya dengan nilai spf (Sun Protecting Factor) dengan konsentrasi 600 ppm, 400 ppm, 200 masing-masing sebagai berikut: $24 \pm 0.31 ; 16 \pm 0.34$; dan $8 \pm 0.3$. Kesimpulan dari penelitian ini Sungkai (Peronema canescens Jack) memiliki aktivitas sebagai antioksidan dan memiliki aktivitas tabir surya sehingga berpotensi dikembangkan menjadi natural skin care.
\end{abstract}

Kata kunci: Peronema canescens Jack, tabir surya, antioksidan

\section{ABSTRACT}

Indonesia, which is located in the tropics, causes people's skin to easily experience premature aging and tan. Most of these cosmetic products contain dangerous synthetic chemicals. For this reason, cosmetic products with natural active ingredients or phytocosmetics that are effective and safe to use need to be developed. One of the typical natural plant plants from South Kalimantan that has the potential to be developed as a cosmetic preparation is Sungkai (Peronema canescens Jack). The aim of the study was to determine the antioxidant activity and sunscreen activity of Sungkai leaves. The method used for the determination of antioxidant activity is the DPPH method using a uv-vis spectrophotometer and for the determination of sunscreen activity using a $u v$-vis spectrophotometer. The results showed that the $P$. canescens plant extract contained anthraquinones, flavonoids, saponins, tannins, and phenols. P.canescens plants have an Inhibitory 
Jurnal Ilmiah Ibnu Sina, 6(2), Oktober 2021, 322-330

p-ISSN: 2502-647X; e-ISSN: 2503-1902

Concentration 50 (IC50) of 42.219 19.440 ppm and have sunscreen activity with spf (Sun Protecting Factor) values with concentrations of 600 ppm, 400 ppm, 200 respectively as follows: $24 \pm 0.31 ; 16 \pm 0.34$; and $8 \pm 0.3$. The conclusion of this study Sungkai (Peronema canescens Jack) has antioxidant activity and has sunscreen activity so that it has the potential to be developed into natural skin care.

Keywords: Peronema canescens Jack, sunscreen, antioxidan

\section{PENDAHULUAN}

Kosmetika merupakan salah satu kebutuhan sekunder yang semakin terus meningkat karena adanya keinginan manusia yang selalu ingin semakin cantik khususnya wanita. Jumlah penduduk sekitar 250 juta jiwa, menjadikan Indonesia pasar yang menjanjikan bagi perusahaan kosmetik. Menurut Global Bussiness Guide menyatakan bahwa di Indonesia, pertumbuhan volume penjualan industri kosmetik didongkrak oleh permintaan yang meninggi dari kelas menengah. Adanya tren back to nature membuat industri kosmetik yang berbasis dari herbal berprospek cerah. Penggunaan produk yang dahulu hanya sebagai kebutuhan sekunder kini berkembang menjadi kebutuhan primer, terutama bagi perempuan. Dengan adanya tren tersebut maka berkembanglah istilah fitokosmetik.Fitokosmetik merupakan cabang ilmu dari kosmetik yang membahas mengenai kosmetika yang berasal dari bahan-bahan alam.

Semakin maraknya produkproduk kecantikan dari luar negeri seperti dari Korea dan Jepang yang menjadikan Indonesia pangsa pasar yang potensial. Selain itu juga kondisi Indonesia yang terletak di daerah tropis yang menyebabkan kulit masyarakatnya mudah mengalami penuaan dini dan kecokelatan. Paparan sinar UV dari matahari di daerah tropis menjadi sumber radikal bebas penyebab penuaan kulit (Ardhi 2011) dan meningkatkan aktivitas enzim tirosinase pensintesa pigmen melanin sehingga warna kulit menjadi semakin kecoklatan (Batubara dan Adfa 2013). Namun, produk kosmetik tersebut sebagian besar mengandung bahan kimia sintetik yang berbahaya. Butil hidroksi anisol dan butil hidroksi toluen sebagai antioksidan sintetis pencegah penuaan kulit bersifat karsinogenik (Ariyani et al. 2008). Senyawa pemutih kulit seperti asam kojat dan hidrokuinon bersifat 
Jurnal Ilmiah Ibnu Sina, 6(2), Oktober 2021, 322-330

p-ISSN: 2502-647X; e-ISSN: 2503-1902

karsinogenik dan menyebabkan iritasi kulit, kulit memerah, panas, dan gatal (Miyazawa et al. 2006, Al-Ash'ary et al. 2010). Untuk itu, produk kosmetik berbahan aktif alami yang efektif serta aman digunakan perlu dikembangkan.

Indonesia merupakan negara dengan kekayaan alam yang melimpah, hampir segala jenis tanaman dapat tumbuh di Indonesia. Pemanfaatan tumbuhan-tumbuhan sebagai bahan baku kosmetik telah ada sejak 3500 tahun yang lalu. Penggunaan kosmetik dalam bentuk sederhana dan dengan cara tradisional, telah digunakan oleh manusia sejak dahulu (Wasitaatmadja, 1997). Salah satu tanaman bahan alam yang khas dari Kalimantan Selatan yang berpotensi dikembangkan sebagai sediaan kosmetik adalah Sungkai (Peronema canescens Jack). Sungkai memiliki aktivitas antioksidan yang sangat aktif. Beberapa penelitian membuktikan bahwa zat ekstraktif tumbuhan berpotensisebagai senyawa aktif antioksidan dan inhibitor enzim tirosinase. Senyawa antioksidan alami dari golongan fenolik tumbuhan mampu menghambat penuaan dini kulit (Stallings \& Lupo 2009). Oleh karena itu perlu dilakukan penelitian mengenai uji aktivitas tabir surya dan antioksidan ekstrak etanol daun Sungkai (Peronema canescens Jack).

\section{METODE PENELITIAN}

Pengumpulan dan pengolahan simplisia Daun Sungkai

Pengumpulan dan pengolahan simplisia diawali dengan tahap sortasi basah terlebih dahulu, yaitu proses pemisahan bagian tanaman yang akan digunakan dengan bahan yang tidak digunakan dari tanaman utuh. Bagian yang digunakan yaitu batang yang segar dan tidak rusak. Setelah dilakukan pemisahan kemudian batang yang sudah terpilih dicuci dengan air bersih untuk menghilangkan kotoran, tanah, debu, maupun serangga yang menempel. Batang yang telah bersih kemudian dipotong kecil menjadi haksel. Haksel kemudian dikeringanginkan di tempat yang teduh dan tidak terkena sinar matahari langsung. Sortasi kering dilakukan terhadap haksel agar benarbenar bersih. Setelah itu haksel dihaluskan hingga menjadi serbuk kasar, disimpan dalam wadah tertutup dan terhindar dari sinar matahari.s[?] 
Jurnal Ilmiah Ibnu Sina, 6(2), Oktober 2021, 322-330

p-ISSN: 2502-647X; e-ISSN: 2503-1902

\section{Pembuatan ekstrak}

Metode ekstraksi yang digunakan pada penelitian ini adalah metode maserasi. Sebanyak 1000 gram serbuk daun Sungkai direndam menggunakan pelarut etanol $96 \%$ sebanyak $1 \mathrm{~cm}$ di atas permukaan rendaman serbuk atau dengan perbandingan sampel dan pelarut 1:5. Maserasi dilakukan 3x24 jam dan pergantian pelarut dilakukan setiap 1x24 jam disertai dengan pengadukan. Maserat yang diperoleh diuapkan dengan rotary evaporator pada suhu $58^{\circ} \mathrm{C}$.

\section{Aktivitas antioksidan}

Metode yang digunakan mengikuti Ye et al. (2009) dengan modifikasi. Larutan sampel (dengan konsentrasi berbeda) sebanyak $1 \mathrm{~mL}$ ditambahkan $3 \mathrm{~mL}$ larutan DPPHetanol Pa segar. Campuran sampelDPPH dihomogenkan dengan vorteks agar reaksi berjalan sempurna. Campuran larutan kemudian diinkubasi dalam vial tertutup rapat agar terlindung dari cahaya pada suhu ruang $\left(27-30^{\circ} \mathrm{C}\right)$ selama 30 menit. Hasil inkubasi diukur serapannya dengan spektrofotometer UV-Vis pada panjang gelombang maksimum.
Perlakuan yang sama diberikan untuk blanko.

\section{Penentuan Aktivitas Tabir Surya}

Penentuan aktivitas tabir surya dilakukan dengan menentukan nilai SPF spektrofotometri $U V$-Vis. Ekstrak kering kulit dibuat dengan konsentrasi 600, 400, dan 200 ppm menggunakan etanol p.a. Ekstrak dibaca serapannya dengan panjang gelombang antara 290-320 nm setiap interval $5 \mathrm{~nm}$. Blanko yang digunakan adalah etanol p.a. Hasil absorbansi digunakan untuk menghitung nilai SPF dengan persamaan rumus Mansur (1986).

\section{HASIL DAN PEMBAHASAN}

\section{Uji aktivitas antioksidan}

Uji aktivitas antioksidan didahului dengan menentukan aktivitas antioksidan dari kuersetin sebagai kontrol positif untuk dapat memastikan metode yang digunakan dapat menunjukkan hasil yang optimal. Aktivitas penangkapan radikal bebas oleh keursetin telah terbukti sehingga dapat digunakan sebagai kontrol positif pada metode DPPH ini (Salamah \& Erlinda, 2015). Larutan standar kuersetin dibuat menjadi 6 konsentrasi yaitu, 1, 2, 3, 4, 
Jurnal Ilmiah Ibnu Sina, 6(2), Oktober 2021, 322-330

p-ISSN: 2502-647X; e-ISSN: 2503-1902

5, dan 6 ppm yang masing-masingnya direaksikan dengan larutan DPPH 0,4 $\mathrm{mM}$ dan diinkubasi selama 46 menit kemudian dibaca menggunakan panjang gelombang $519 \mathrm{~nm}$. Grafik hubungan konsentrasi dengan persen inhibisi larutan kuersetin dapat dilihat pada Gambar 1.

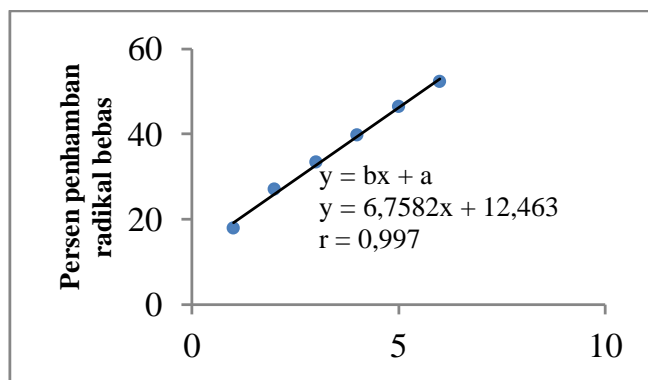

Gambar 1. Grafik hubungan antara konsentrasi larutan kuersetin dengan persen penghambatan radikan bebas

Tabel 1. Persen inhibisi larutan pembanding kuersetin

\begin{tabular}{ccccc}
\hline \multirow{2}{*}{$\begin{array}{c}\text { Konsentras } \\
\mathbf{i}(\mathbf{p p m})\end{array}$} & \multicolumn{3}{c}{ \% Inhibisi } & $\begin{array}{l}\text { Rerata } \\
\text { \% } \\
\text { inhibisi }\end{array}$ \\
\cline { 2 - 5 } & $\mathbf{1}$ & $\mathbf{2}$ & $\mathbf{3}$ & 17,883 \\
\hline 1 & 15,384 & 16,848 & 21,418 & 26,964 \\
2 & 28,165 & 24,283 & 28,444 & 33,431 \\
3 & 37,810 & 28,990 & 33,492 & 39,743 \\
4 & 47,810 & 36,152 & 35,266 & 36,436 \\
5 & 60,591 & 41,132 & 37,585 & 46,436 \\
6 & 70,650 & 47,271 & 38,813 & 52,245 \\
\hline
\end{tabular}

Tabel 2. Aktivitas antioksidan kuersetin

\begin{tabular}{c|c|c}
\hline $\mathbf{I C}_{\mathbf{5 0}}$ (ppm) & $\bar{x} \mathbf{I C}_{\mathbf{5 0} \pm \mathbf{S D}}$ & \%RSD \\
\hline 4,102 & & \\
6,428 & $6,253 \pm 2,07$ & $33,089 \%$ \\
8,229 & & \\
\hline
\end{tabular}

Hasil regresi linear yang diperoleh dari hubungan konsentrasi kuersetin dan persen inhibisi adalah y
$=6,768 x+12,463$ dengan koefisien relasi (r) adalah 0,997. Nilai $\mathrm{IC}_{50}$ yang diperoleh menunjukkan aktivitas antioksidan dengan kategori sangat aktif karena konsetrasi penghambatan kurang dari 50 ppm. Berdasarkan hal tersebut maka diketahui semakin tinggi persen penghambatan radikal bebas yang didapatkan (Agustikawati et al., 2017). Sesuai dengan Sami et al. (2016) nilai IC $_{50}$ kuersetin sebesar 6,263 ppm tergolong dalam kategori sangat aktif.

Pengujian aktivitas antioksidan ekstrak etanol daun P.canescens menggunakan 6 konsentrasi yaitu 10, 20, 30, 40, 50 dan 60 ppm.

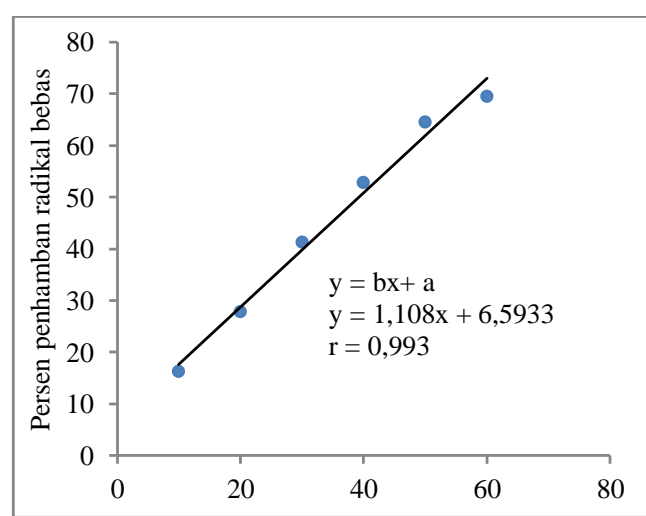

Gambar 2. Grafik hubungan antara konsentrasi ekstrak etanol daun $P$. canescens dengan persen penghambatan radikal bebas

Tabel 3. Aktivitas antioksidan ekstrak etanol daun $P$. canescens 
Jurnal Ilmiah Ibnu Sina, 6(2), Oktober 2021, 322-330

p-ISSN: 2502-647X; e-ISSN: 2503-1902

\begin{tabular}{lll}
\hline $\begin{array}{l}\text { IC }_{\mathbf{5 0}} \\
\text { ppm) }\end{array}$ & $\bar{x}$ IC $_{\mathbf{5 0}} \pm$ SD & \%RSD \\
\hline 64,659 & & \\
31,514 & $42,219 \pm 19,440$ & $46,044 \%$ \\
30,486 & & \\
\hline
\end{tabular}

Hasil persamaan regresi linear yang diperoleh dari hubungan konsentrasi ekstrak etanol daun $P$. canescens dengan persen inhibisi yaitu $y=1,107 x+6,593$ dengan koefisien relasi (r) 0,993. Berdasarkan persamaan tersebut didapatkan $\mathrm{IC}_{50}$ ekstrak etanol daun $P$. canescens sebesar 42,219 ppm yang dapat menghambat aktivitas radikal bebas DPPH. Perubahan intensitas warna pada DPPH dapat menjad indikasi adanya aktivitas antioksidan pada sampel yang direaksikan (Agustikawati et al., 2017). Hasil menunjukan aktivitas penghambatan radikal bebas yang sangat aktif. Menurut Widodo et al. (2019) nilai $\mathrm{IC}_{50}$ ekstrak metanol daun $P$. canescens sebesar 9,389 ppm. Perbedaan nilai $\mathrm{IC}_{50}$ karena adanya perbedaan konsentrasi DPPH, pelarut sampel yang digunakan serta daerah tumbuh sampel (Widodo et al., 2019).

\section{Aktivitas Tabir Surya}

Tabel 4. Hasil Absorbansi konsentrasi 600 ppm

\begin{tabular}{|c|c|c|c|c|c|c|}
\hline \multirow{2}{*}{$\lambda$} & \multicolumn{3}{|c|}{ Replikasi Absorbansi } & \multicolumn{3}{|c|}{ A $x \operatorname{EE} \times \mathbf{I}$} \\
\hline & 1 & 2 & 3 & 1 & 2 & 3 \\
\hline 290 & 2.37 & 2.37 & 2.36 & 0.036 & 0.036 & 0.035 \\
\hline 295 & 2.39 & 2.37 & 2.36 & 0.195 & 0.194 & 0.192 \\
\hline 300 & 2.45 & 2.42 & 2.39 & 0.703 & 0.695 & 0.689 \\
\hline 305 & 2.49 & 2.46 & 2.43 & 0.817 & 0.805 & 0.798 \\
\hline 310 & 2.56 & 2.52 & 2.49 & 0.478 & 0.469 & 0.463 \\
\hline 315 & 2.66 & 2.6 & 2.57 & 0.223 & 0.218 & 0.215 \\
\hline 320 & 2.81 & 2.8 & 2.69 & 0.051 & 0.050 & 0.048 \\
\hline \multicolumn{4}{|c|}{ Total } & 2.502 & 2.47 & 2.44 \\
\hline \multicolumn{4}{|c|}{ Mean } & \multicolumn{3}{|c|}{2.470} \\
\hline \multicolumn{4}{|c|}{ SD } & \multicolumn{3}{|c|}{0.031} \\
\hline
\end{tabular}

surya dilakukan dengan menentukan nilai SPF secara in vitro dengan menggunakan alat spektrofotometer UV-Vis pada panjang gelombang 290$320 \mathrm{~nm}$. Metode yang digunakan untuk menentukan nilai SPF mengacu pada metode yang dikembangkan oleh Mansur (1986). Ekstrak diencerkan dengan konsentrasi 500 ppm dan dibaca pada spektrofotometer UV-Vis pada panjang gelombang 290-320 nm. Pemilihan konsentrasi 500 ppm karena pada konsentrasi tersebut sudah dapat mewakili perhitungan nilai SPF dari hasil absorbansinya yang dibaca pada Spektrofotometer UV-Vis. Nilai SPF berbanding lurus dengan konsentrasi ekstrak. Semakin besar konsentrasi ekstrak yang ditambahkan akan meningkatkan nilai SPF. 
Jurnal Ilmiah Ibnu Sina, 6(2), Oktober 2021, 322-330

p-ISSN: 2502-647X; e-ISSN: 2503-1902

Tabel 5. Hasil Absorbansi konsentrasi 400

\begin{tabular}{|c|c|c|c|c|c|c|}
\hline \multirow{2}{*}{$\Lambda$} & \multicolumn{3}{|c|}{ Replikasi Absorbansi } & \multicolumn{3}{|c|}{ A x EE x I } \\
\hline & 1 & 2 & 3 & 1 & 2 & 3 \\
\hline 290 & 1.62 & 1.61 & 1.61 & 0.024 & 0.024 & 0.024 \\
\hline 295 & 1.62 & 1.60 & 1.60 & 0.133 & 0.131 & 0.131 \\
\hline 300 & 1.67 & 1.63 & 1.64 & 0.480 & 0.468 & 0.470 \\
\hline 305 & 1.71 & 1.65 & 1.65 & 0.561 & 0.541 & 0.542 \\
\hline 310 & 1.76 & 1.69 & 1.69 & 0.328 & 0.314 & 0.315 \\
\hline 315 & 1.84 & 1.74 & 1.74 & 0.155 & 0.146 & 0.146 \\
\hline 320 & 2.02 & 1.85 & 1.86 & 0.036 & 0.033 & 0.033 \\
\hline \multicolumn{4}{|c|}{ Total } & 1.718 & 1.658 & 1.661 \\
\hline \multicolumn{4}{|c|}{ Mean } & \multicolumn{3}{|c|}{1.679} \\
\hline \multicolumn{4}{|c|}{ SD } & \multicolumn{3}{|c|}{0.034} \\
\hline
\end{tabular}

Tabel 6. Hasil Absorbansi konsentrasi 200 ppm

\begin{tabular}{|c|c|c|c|c|c|c|}
\hline \multirow{2}{*}{$\lambda$} & \multicolumn{3}{|c|}{ Replikasi Absorbansi } & \multicolumn{3}{|c|}{$A \times \mathbf{E E} \times I$} \\
\hline & 1 & 2 & 3 & 1 & 2 & 3 \\
\hline 290 & 0.83 & 0.818 & 0.81 & 0.012 & 0.012 & 0.013 \\
\hline 295 & 0.82 & 0.814 & 0.80 & 0.067 & 0.067 & 0.066 \\
\hline 300 & 0.86 & 0.83 & 0.82 & 0.247 & 0.239 & 0.235 \\
\hline 305 & 0.88 & 0.832 & 0.82 & 0.288 & 0.273 & 0.269 \\
\hline 310 & 0.92 & 0.843 & 0.83 & 0.171 & 0.157 & 0.155 \\
\hline 315 & 0.95 & 0.864 & 0.85 & 0.079 & 0.072 & 0.071 \\
\hline 320 & 1.03 & 0.92 & 0.90 & 0.019 & 0.017 & 0.016 \\
\hline \multicolumn{4}{|c|}{ Total } & 0.882 & 0.836 & 0.826 \\
\hline \multicolumn{4}{|c|}{ Mean } & \multicolumn{3}{|c|}{0.848} \\
\hline \multicolumn{4}{|c|}{ SD } & \multicolumn{3}{|c|}{0.03} \\
\hline
\end{tabular}

Tabel 7. Nilai SPF Ekstrak Etanol P.canescens

\begin{tabular}{cc}
\hline Konsentrasi (ppm) & Nilai SPF \\
\hline 600 & $24 \pm 0.31$ \\
400 & $16 \pm 0.34$ \\
200 & $8 \pm 0.3$ \\
\hline
\end{tabular}

Angka SPF menyatakan kemampuan suatu zat dapat melipatgandakan sebanyak angka kali daya tahan alami kulit seseorang sehingga aman berada di bawah sinar matahari tanpa mengalami eritema. Penggunaan SPF yang lebih tinggi hanya memberikan perlindungan yang meningkat hanya sedikit tetapi resiko kulit teiritasi makin besar karena kulit makin banyak terpapar zat kimia (Nofianty, 2008). Sehingga dapat disimpulkan ekstrak etanol sungkai memiliki potensi sebagai bahan aktif tabir surya.

Penelitian yang dilakukan oleh Wungkana \& Momuat (2013) memberikan informasi bahwa ekstrak etanol tongkol jagung dengan konsentrasi 500 ppm diperoleh nilai SPF 10. Penelitian Maheshwar et al (2010) 500 ppm ekstrak mentimun memiliki nilai SPF 7 , sedangkan penelitian Malsawmtluangi et al (2013) dengan konsentrasi 100 ppm ektsrak mentimun memiliki nilai SPF 2. Hal ini menunjukkan bahwa nilai SPF dipengaruhi oleh konsentrasi senyawa aktif yang terkandung didalam ekstrak. Semakin tinggi konsentrasi semakin banyak senyawa yang dapat menyerap sinar ultraviolet yang masuk ke kulit sehingga nilai SPF semakin tinggi. 
Jurnal Ilmiah Ibnu Sina, 6(2), Oktober 2021, 322-330

p-ISSN: 2502-647X; e-ISSN: 2503-1902

Hasil yang diperoleh dari uji aktivitas tabir surya dan antioksidan dari ekstrak etanol P.canescens ini menunjukkan bahwa aktivitas tabir surya dikategorikan memiliki proteksi ultra dan aktivitas antioksidan dikategori sangat aktif. Hal tersebut menunjukkan bahwa pada ekstrak etanol daun P.canescens, hasil uji aktivitas antioksidan dan aktivitas tabir surya berbanding lurus. Senyawa antioksidan alami dari golongan fenolik tumbuhan mampu menghambat penuaan dini kulit (Stallings \& Lupo 2009).

\section{KESIMPULAN}

Tanaman P.canescens memiliki Inhibitory Concentration 50 ( $\left.\mathrm{IC}_{50}\right)$ sebesar 42,219 $\pm 19,440$ ppm dan memiliki aktivitas tabir surya dengan nilai spf (Sun Protecting Factor) dengan konsentrasi 600 ppm, 400 ppm, 200 masing-masing sebagai berikut: $24 \pm 0.31 ; 16 \pm 0.34$; dan $8 \pm 0.3$. Kesimpulan dari penelitian ini Sungkai (Peronema canescens Jack) memiliki aktivitas sebagai antioksidan dan memiliki aktivitas tabir surya sehingga berpotensi dikembangkan menjadi natural skin care.

\section{UCAPAN TERIMA KASIH}

Ucapan terima kasih disampaikan kepada Hibah Penelitian Dosen Wajib Meneliti Universitas Lambung Mangkurat yang telah mendanai penelitian ini sehingga dapat terlaksana dengan baik.

\section{DAFTAR PUSTAKA}

Agustikawati, N., Y. Andayani, \& D. Suhendra. (2017). Uji Aktivitas Antioksidan dan Penapisan Fitokimia dari Ekstrak Daun Pakoasi dan Kluwih Sebagai Sumber Antioksidan Alami. Jurnal Penelitian Pendidikan IPA. 3: 60-67.

Ardhi AM. (2011). Radikal bebas dan peran antioksidan dalam mencegah penuaan. Medicinus 24(1):3-9.

Ariyani F, Amin I, Fardiaz D, Budiyanto S. (2008). Aplikasi ekstrak daun sirih (Piper betle Linn) dalam menghambat oksidasi lemak jambal patin (Pangasius hypophthalmus). JPBKP 3(2):157-169.

Batubara I, Adfa M. (2013). Potensi daun kayu bawang (Protium javanicum) sebagai penghambat kerja enzim tirosinase. J Sains Mat. 1(2):52-56.

Maheshwar, H. G., B. S. Patil \& D. Prashant. (2010). Comparative Sun Protection Factor Determination of Fresh Fruits Extract of Cucumber vs 
Jurnal Ilmiah Ibnu Sina, 6(2), Oktober 2021, 322-330

p-ISSN: 2502-647X; e-ISSN: 2503-1902

Marketed Cosmetic

Formulation. Research Journal

of Pharmaceutical, Biological and Chemical Sciences. 1 (3): 55-59.

Malsawmtluangi, C., D. K. Nath, I. Jamatia, Lianhimgthangi, E. Zarzoliana, L. Pachuau. (2013). Determination of Sun Protection Factor (SPF) number of some aqueous herbal extracts. Journal of Applied Pharmaceutical Science. 3 (09): 150-151

Miyazawa, Mitsuo, Tamura N. (2006). Inhibitory compound of tyrosinase activity from the Sprout of Polygonum hydropiper L. J Biol Pharm Bull. 30(3):595-597.

Salamah, N. \& E. Widyasari. (2015). Aktivitas Antioksidan Ektrak Metanol Daun Kelengkeng (Euphoria longan (L) Steud.) dengan Metode Penangkapan Radikal 2,2'-Difenil-1Pikrilhidrazil. Pharmaciana. 5: 25-34.

Sami, F. J., S. Nur., S. Kursia., S. A. Gani., T. Reski \& Sidupa. (2016). Uji Aktivitas Antioksidan dari beberapa ekstrak kulit batang Jamblang (Syzygium cumini) menggunakan metode peredaman radikal 2,2-diphenyl1-picrylhydrazyl (DPPH). JF FIK UINAM. 4 : 130-138.

Stalling AF, Lupo MP. (2009). Practical Uses of Botanicals in Skin Care. J. Clin Aesth Derm. 2(1): 36-40.

Wasitaatmadja. (1997). Penuntun Kosmetik Medik. Jakarta: Universitas Indonesia.
Widodo, H., S. Sismindari, W. Asmara \& A. Rohman. (2019). Antioxidant Activity, Total Phenolic and Flavonoid Contents of Seleced Medical Plants Used For Liver Disease and Its Classification with Chemometrics. Journal of Applied Pharmaceutical Science. 9: 99-105.

Wungkana, I., E. Suryanto, \& L. Momuat. (2013) . Aktivitas Antioksidan dan Tabir Surya Fraksi Fenolik Limbah Tongkol Jagung (Zea mays L.). Jurnal Ilmiah Farmasi Unsrat. 2 (4) : 149-154. 